East African Medical Journal Vol. 81 No. 7 July 2004

CURRENT PRACTICES AND MEDICO-LEGAL ASPECTS OF PRE-OPERATIVE CONSENT

O. C., Osime, FMCS., FICS; Lecturer 1, Department of Surgery, O. Okojie, FMCPH, Senior Lecturer, Department of Community Health, F. Osadolor, F. LLM., Lecturer 1, Faculty of Law and S. Mohammed, MBBS., Resident Doctor, Department of Community Health, University of Benin, PMB 1154, Benin City, Nigeria

Request for reprints to: Dr. O. C., Osime, Department of Surgery, University of Benin, PMB 1154, Benin City, Nigeria

\title{
CURRENT PRACTICES AND MEDICO-LEGAL ASPECTS OF PRE-OPERATIVE CONSENT
}

\author{
O. C. OSIME, O. OKOJIE, F. OSADOLOR and S. MOHAMMED
}

\begin{abstract}
Background: Written informed consent is a pre requisite for surgical intervention as it provides the forum for the patient to appreciate implications of the procedure and the doctor to explain details and effects of the surgery.

Objectives: To evaluate the practice of obtaining informed consent pre-operatively by surgeons in Benin City and proffer solutions that would enhance its practice.

Design: Cross-sectional study involving surgical patients or their relations or gurdian (in cases involving minors and unconscious patients) who were interviewed with structured ended questionnaires.

Setting: Study was carried out at the University of Benin Teaching Hospital, Benin City, between 5th July and 6th September 2002.

Results: One hundred and thirty-three respondents; 53(39.2\%) males and $80(60.2 \%)$ females were interviewed. Documentations regarding consent were noted in $118(88.7 \%)$ cases. Of these, $\mathbf{7 4 . 6 \%}$ felt they had enough time to reflect on the consent obtained while $48(36.1 \%)$ respondents were meeting the individual who obtained their consent for the first time. The content of information offered patients prior to obtaining consent was found to be significantly related to the levels of education $\left(X^{2}=31.44 ; P<0.001\right)$. Over a hundred respondents were not informed of risk of procedure. Nonetheless over $50 \%$ of respondents felt satisfied with information supplied.

Conclusion: The quality of consent obtained from the average patient fell below expected standard. There is need for greater awareness amongst administrators of consent on the essence of improving quality of information given and mode of obtaining consent from patients.
\end{abstract}

\section{INTRODUCTION}

The issue of obtaining consent from surgical patients is one that is becoming increasingly fascinating as more and more persons are increasingly becoming aware of their right to information on surgical care $(1,2)$. Almost all surgical procedures are irreversible. The need, therefore for explanation on the implication of the surgery to be performed cannot be overemphasized.

Informed consent should be based on shared decision between doctor and patient, with the doctor understanding the relevant values of the patient and the patient understanding the nature of the disease and intervention, including risks and benefits. This practice has developed rapidly since the 1950's when it was first introduced, reflecting recent changes in the practice of medicine that respect the increase in patient's autonomy $(3,4)$. The objective of the written consent form is to document that the process of informed consent has taken place and is generally accepted that all surgical procedures require a written consent.
Until recently, most people in our society were not aware of their own rights even when it involved medical care. As the legal system in our society advances, coupled with the widespread use of advanced information technology, it follows that majority of our patients would become conscious of their legal rights. Thus, the issue of litigation known to be very rampant in the western world may soon become the order of the day in Nigeria. Furthermore, with the introduction of the National Health Insurance Scheme in the country the medical doctor needs to know his rights and limitations; otherwise, he may be tagged as "high risks" to the insurance company. Despite this stated reality, most doctors do not pay much attention to the legal aspects of medical practice. For example, it is common knowledge that some doctors carry out surgical procedures on patients without first obtaining their consent for operation. The aim of this study was to evaluate the issue of informed consent before surgical procedures and to suggest ways that will ensure improved use before surgery. 


\section{MATERIALS AND METHODS}

This cross-sectional study which was carried out at the University of Benin Teaching Hospital (UBTH) Benin City covered the period between 5th July and 6th September 2002. Participants included all patients and informants (in situations where patients were minors, presented unconscious or in physical distress). Respondents were from all the units that carry out surgical procedures on patients and informed consent was obtained from the patients before being included in the study. The questionnaires which were interviewer administered consisted of two parts - the demographic section and the section that aimed at examining the issue of informed consent through adequately tailored open and close ended questions. The patients or their informants were made to complete the forms in the presence of the doctor. Explanations were given about each question where the patients or informants needed such. For those patients or informants that are not educated, the doctor had to complete their forms. Some of the questions asked included the type of operation (whether major or minor or whether elective or emergency operation) carried out, the educational status of the patient or their informants. We also sought to know the status of the doctors that obtained consents and the amount of information that was made available to the patients or their informants before consent was obtained. Findings were collected and analysed using simple percentage and numerical tabular representations.

\section{RESULTS}

A total of 133 patients were studied and their age and sex distribution are presented in Table 1 . Majority of them were in the 31 - 40 years age group while age groups $0-10$ and $71-80$ years accounted for the least number of patients. There were more female patients than males. Different aspects of the consent procedure were assessed in Table 2. A total of 118 patients $(88.7 \%)$ had their consent documented and 48 patients $(36.1 \%)$ claimed they met the person who obtained their consent for the first time.

Table 1

Age distribution of the patients

\begin{tabular}{lrrr}
\hline Age range (years) & $\begin{array}{c}\text { Males } \\
\text { No. }(\%)\end{array}$ & $\begin{array}{c}\text { Females } \\
\text { No. }(\%)\end{array}$ & $\begin{array}{c}\text { Total }(\%) \\
\text { No. }(\%)\end{array}$ \\
\hline $0-10$ & $3(2.3)$ & $(0)$ & $3(2.3)$ \\
$11-20$ & $9(6.8)$ & $15(11.3)$ & $24(18.0)$ \\
$21-30$ & $13(9.8)$ & $14(10.5)$ & $27(20.3)$ \\
$31-40$ & $10(7.5)$ & $21(15.8)$ & $31(23.3)$ \\
$41-50$ & $7(5.3)$ & $13(9.8)$ & $20(15.0)$ \\
$51-60$ & $8(6.0)$ & $7(5.3)$ & $15(11.3)$ \\
$61-70$ & $2(1.5)$ & $2(6.0)$ & $3(7.5)$ \\
$71-80$ & $1(0.8)$ & $80(60.2)$ & $133(100)$ \\
\hline Total & $53(39.8)$ & &
\end{tabular}

Table 2

Different aspects of consent procedure assessed $(n=113)$

\begin{tabular}{|c|c|c|c|c|c|c|}
\hline \multirow[t]{3}{*}{ Aspect of procedure } & \multicolumn{3}{|c|}{ Response } & \multicolumn{3}{|c|}{ No response } \\
\hline & \multicolumn{2}{|c|}{ Yes } & \multicolumn{2}{|c|}{ No } & \multirow[b]{2}{*}{ No. } & \multirow[b]{2}{*}{$(\%)$} \\
\hline & No. & $(\%)$ & No. & $(\%)$ & & \\
\hline Agreed to have operation & 123 & 92.4 & 9 & 6.8 & 1 & 0.8 \\
\hline Documented consent & 118 & 88.7 & 15 & 11.3 & - & - \\
\hline $\begin{array}{l}\text { Met the doctor who obtained } \\
\text { the consent for the first time }\end{array}$ & 48 & 36. 1 & 77 & 57.9 & 8 & 6.0 \\
\hline $\begin{array}{l}\text { Enough time for reflection } \\
\text { before decision }\end{array}$ & 88 & 66.2 & 29 & 21.8 & 16 & 12.0 \\
\hline Satisfied with outcome of operation & 115 & 86 & 18 & 13.5 & - & - \\
\hline
\end{tabular}


Table 3

Type of information made available to patient or relatives before consent was obtained

\begin{tabular}{|c|c|c|c|c|c|c|c|c|}
\hline \multirow{3}{*}{$\begin{array}{l}\text { Information given } \\
\text { or received from } \\
\text { the patients before } \\
\text { consent was obtained }\end{array}$} & \multicolumn{8}{|c|}{$\begin{array}{l}\text { Responses from various categories of patient in } \\
\text { terms of levels of education }\end{array}$} \\
\hline & \multicolumn{2}{|c|}{ No education } & \multicolumn{2}{|c|}{$\begin{array}{l}\text { Primary } \\
\text { education }\end{array}$} & \multicolumn{2}{|c|}{$\begin{array}{l}\text { Secondary } \\
\text { education }\end{array}$} & \multicolumn{2}{|c|}{$\begin{array}{l}\text { Tertiary } \\
\text { education }\end{array}$} \\
\hline & No. & $(\%)$ & No. & $(\%)$ & No. & $(\%)$ & No. & $(\%)$ \\
\hline Need for operation & 1 & 33.3 & 27 & 81.8 & 47 & 95.9 & 48 & 100 \\
\hline Nature of operation & 0 & 0 & 39 & 27.3 & 39 & 79.6 & 45 & 93.8 \\
\hline Benefit of operation & 1 & 33.3 & 8 & 24.2 & 40 & 81.6 & 46 & 95.8 \\
\hline $\begin{array}{l}\text { Associate risks of } \\
\text { operation }\end{array}$ & 0 & 0 & 2 & 6.1 & 8 & 16.3 & 15 & 31.2 \\
\hline $\begin{array}{l}\text { Given opportunity at ask } \\
\text { questions or make } \\
\text { comments }\end{array}$ & 1 & 33.3 & 8 & 24.2 & 34 & 69.4 & 38 & 79.2 \\
\hline $\begin{array}{l}\text { Satisfaction with } \\
\text { amount of } \\
\text { preoperational } \\
\text { information }\end{array}$ & 1 & 33.3 & 30 & 90.9 & 41 & 83.7 & 45 & 93.8 \\
\hline
\end{tabular}

$\mathrm{X}^{2}=31.435, \mathrm{df}=15 \mathrm{p}=<0.001$

Table 4

Problems encountered by respondents while consent was being obtained

\begin{tabular}{lll}
\hline Observation & No. & $(\%)$ \\
\hline None & 100 & 85 \\
Language barrier & 2 & 1.7 \\
Use of technical terms & 6 & 5.0 \\
Poor communication skills & 3 & 2.5 \\
Lack of time on the part of & 5 & 4.1 \\
the doctors (in haste) & 2 & 1.7 \\
No response & 118 & 100 \\
\hline Total & & \\
\hline
\end{tabular}

Eight eight (66.2\%) felt they had enough time for reflection before their consent was obtained. Table 1 shows that there is a significant difference in the kind of information given to respondents of different educational levels $\left(\mathrm{X}^{2}=31.435, \mathrm{P}<0.001\right)$. A majority of $108(81.2 \%)$ said they were not informed of the risks associated with the procedures. However, most of them were told of the need, nature and benefits of the operation and given opportunity to ask questions. An appreciable number (88\%) felt satisfied with the information they were given.

\section{DISCUSSION}

The minimal requirement necessary to obtain a legally acceptable 'consent' from a surgical patient is one in which the broad nature of the surgery to be performed is made known to the patient in understandable terms(5). Informed consent usually requires patient's capacity, adequate disclosure of information and voluntariness. Capacity refers to the ability to understand the information relevant to making a decision and to appreciate the reasonably foreseeable consequences of decision or lack of decision. Disclosure refers to the provision of relevant information and its comprehension by the patient. Voluntariness refers to the freedom of a person to make a treatment decision. The act of obtaining informed consent in surgical practice has ethical, social and medico-legal dimensions $(6,7)$.

From the present study, consent was obtained from 118 patients out of the total of 133 that had surgery. Majority of the patients whose consent was not obtained before surgery were those that had minor procedures, 
while two had major operations (and these were not emergencies). The reason for these findings may be that some doctors feel that consent is only necessary when dealing with cases requiring major surgical procedures. But it is to be noted that consent ought to be obtained from all surgical patients going to any surgical procedure. This to some extent serves to protect the doctor should complications arise from a seemingly minor operation.

The quality of consent obtained is another aspect of informed consent. In the present study, the need for operation was not explained to nine patients, while the nature of the operation to be carried out was not explained to 40 patients. This situation is not in keeping with the idea of a valid informed consent. Only 92 patients $(69.2 \%)$ were told the benefit of the operation, while the associated risks of the operation were explained to only 25 patients (18.8\%). This again is not in keeping with the rules of obtaining informed consent as a patient ought to know the benefits and risks associated with the operation they want to undertake and possibly the alternatives available(6,7). On the whole, only 81 patients $(60.9 \%)$ were given the opportunity to ask questions or make some comments. Ideally, opportunity should be given to the patients to ask questions and clarify areas not clear to them $(8,9)$. As a result of not being given opportunity to ask questions, $50 \%$ of the patients interviewed claimed that they were not satisfied with the amount of preoperational information given to them before their consent was obtained. Some claimed they had to give their consent all the same irrespective of not having understood what they were actually signing in order not to be labeled as rude patients with some possible attendant consequences. This amounts to obtaining consent by intimidation and these patients cannot therefore be said to have given their informed consent in the real sense of the word. It is a well established fact in criminal law that consent obtained by threat or intimidation for a surgical procedure is not a valid consent and the doctor can be held liable should anything to wrong with the operation. Even the few patients that were given the opportunity to ask questions complained that they were not given enough time to think about the doctors' decision before their consent was obtained. However, for ideal situations, patients should be given reasonable time to make a decision as to whether or not to have surgery(8).

It was also observed in this study that it was only in $4 \%$ of the cases that the consultants in charge of the cases obtained the consent themselves. Consent was obtained by junior members of the surgical team including house officers in $80 \%$ of the cases. In another $16 \%$, the patients claimed that they did not even know the person that obtained their consent. That meant that the doctors just obtained consent without even making introductions of who they were. Consent for operation should ideally be obtained by the consultant in charge of case or the doctor performing the operation. It can also be obtained by other senior members of the team that understand the details of the proposed operation $(6,7)$. Our finding in this study is in consonance with observation in United Kingdom on doctors' practice on informed consent that the senior doctors are often so busy and so delegate the duty of obtaining consent to the very junior doctors in the team(3).

Eighteen patients had difficulty understanding what the doctor was talking about vis-a-vis consent for operation. However, they had to sign all the same so that their operation would not be cancelled. Five of such patients complained that the doctors were using a lot of technical terms, while eight complained that the doctor had little or no time to explain things to them as doctors often claimed that they were in haste. However, an ideal consent for operation demands that explanation be made to the patients in a manner he/she understands very clearly before consenting to have an operation $(6-9,11)$.

Another trend that emerged from the study was that the more educated the patients were, better the attention given to them by doctors during the process of obtaining consent. In the present study, there was a statistically significant difference between the amount of information given to the educated and uneducated patients. This finding is similar to those from other documented studies(6-8). The reason for this finding is probably because doctors feel that educated patients know their rights vis-a-vis consent. The uneducated is unlikely to know his right and would therefore not insist on details. To him, obtaining consent may just be a formality prior to surgery. Ethically, this is a wrong practice that should be discouraged as doctors are expected to treat all patients equally $(1,2,8,11)$.

In recent times, there has been an increasing incidence of litigation regarding the practice of doctors. As the level of education and awareness in our society increases, it is expected that more cases of litigations involving medical doctors would be seen. From the present study, the quality of consent obtained from patients fall below the expected level. It is recommended that medical jurisprudence be introduced into the curriculum of our medical schools. This will afford the medical students the opportunity of knowing about issues of medicolegal significance and avoid unnecessary litigations. Also, with the recent introduction of the National Health Insurance Scheme, a doctor that is often in and out of litigations may infact become an 'Insurance risk' and thus may find it increasingly difficult to practice. 


\section{REFERENCES}

1. Etchells, E. Informed consent in surgical trials. J. Surg. 1999; 23:1215-1219.

2. Houghton, O.J., Williams, S., Bennett, J.D. and Jones, A.S. Information consent: patients and junior doctors' perceptions of the consent procedure. Clin. Otolaryngol. 1997; 22:515-518.

3. Moore, F.D. Ethical problems special to surgery: surgical teaching, surgical innovation, and the surgeon in managed care. Arch. Surg. 2000; 135:14-16.

4. Palter, S,F. Ethics of clinical trials. Semin Reprod. Endocrinol. 1996; 14:85-92.

5. Henley, L., Benator, S.R., Robertson, B.A., and Ensink, K. Informed consent - a survey of doctors' practices in South Africa. South Afr. Med. J. 1995; 85:1273-1278.
6. Leffal, L.D., Claude, H. and Organ, J. Ethics in research and surgical practice. Amer. J. Surg. 1997; 174:589-591.

7. Finkelstein, D., Smith, M.K. and Faden, R. Informed consent and medical ethics. Arch. Ophthamol. 1993; 11:324-326.

8. Donald, L.P., and Graham, S. In sociology as applied to medicine, 2nd ed., Baillier Tindall (Publishers) 1986; 98-109.

9. Faunce, T.A. Medical disclosure and consent forms: proposal for an international standard. Med-Law. 1997; 16:581-591.

10. Axerod, D.A. and Goold, S.D. Maintaining trust in the surgeon patient relationship; challenges for the new millennium. Arch. Surg. 2000; 135:55-61.

11. Okonkwo, C.O., In Criminal Law in Nigeria, 2nd ed., Spectrum law (publishers); 1992; pp 265-296. 